Julia Oliveira Damasceno ${ }^{1}$

Carolina Pinheiro Batista ${ }^{1}$ Ana Maria Caldeira Oliveira ${ }^{1}$

\title{
A REFORMA TRABALHISTA E SUAS IMPLICAÇÕES PARA A SAÚDE DO TRABALHADOR
}

Labor reform and its implications for workers' health

${ }^{1}$ Universidade de São Paulo. Faculdade de Saúde Pública. São Paulo/SP, Brasil.

Correspondência: Julia Oliveira Damasceno.E-mail: juliadamasceno@hotmail.com

Recebido: 01/04/2019. Aprovado: 28/11/2019. 


\section{RESUMO}

A Lei n. 13.467/2017, conhecida como Reforma Trabalhista, trouxe várias modificações ao texto da Consolidação das Leis do Trabalho. Várias dessas mudanças desrespeitam as normas relativas à saúde do trabalhador, dispostas tanto na Constituição Federal de 1988 quanto na legislação infraconstitucional. O objetivo deste estudo foi identificar e analisar as possíveis implicações da Reforma Trabalhista para a saúde do trabalhador, tendo em vista os regramentos constitucionais. Para o desenvolvimento do estudo, utilizou-se a metodologia qualitativa com adoção da técnica de análise de conteúdo de documentos. Foram analisadas quatro alterações propostas pela Lei n. 13.467/2017, quais sejam: a possibilidade de alterar o enquadramento do grau de insalubridade mediante negociação coletiva; a possibilidade de reduzir o intervalo intrajornada também por negociação coletiva; a possibilidade de trabalho em condições insalubres durante a gravidez/fase de lactação; e a liberação da terceirização de qualquer atividade. Verificou-se que a "modernização" trazida pela reforma trabalhista consiste, na realidade, na desconstrução da estrutura constitucional e infraconstitucional de proteção ao trabalhador, com desrespeito aos padrões de saúde e segurança até então presentes no ordenamento jurídico brasileiro. Como consequência, o estudo aponta para a probabilidade de aumento nos números de acidentes de trabalho e de doenças relacionadas ao trabalho.

\section{Palavras-Chave}

Direito à Saúde na Relação Trabalhista; Reforma Trabalhista; Saúde e Segurança do Trabalhador.

\section{ABSTRACT}

Law 13.467/2017, known as the Labor Reform, brought several modifications to the text of the Consolidation of Labor Laws. Several of these changes disregard the norms related to workers' health, both in the Federal Constitution of 1988 and in the infraconstitutional legislation. The objective of this study was to identify and analyze the possible implications of the Labor Reform for workers' health, considering the constitutional regulations. For the development of the study, the qualitative methodology was used with the adoption of the document content analysis technique. Four amendments proposed by Law 13.467/2017 were analyzed, namely: the possibility of changing the framework of the degree of unhealthiness through collective bargaining; the possibility of reducing the work break also through collective bargaining; the possibility of working in unhealthy conditions during pregnancy/ lactation, and the liberation of outsourcing of any activity. It was found that the "modernization" brought by the labor reform consists, in fact, in the deconstruction of the constitutional and infraconstitutional structure of worker protection, with disregard for health and safety standards hitherto present in the Brazilian legal system. As a consequence, the study points to the likelihood of an increase in the number of accidents at work and work-related diseases.

\section{Keywords}

Right to Health in Labor Relation; Labor Reform; Health and Safety of Workers. 


\section{Introdução}

A Reforma Trabalhista que entrou em vigor no dia 11 de novembro de 2017 surgiu como uma resposta do governo brasileiro a um momento de grave crise econômica. Diante do alto índice de desemprego e da necessidade de impulsionar o crescimento econômico para superar a recessão, foi aprovada a Lei n. 13.467/2017 ${ }^{1}$, que resultou em diversas alterações ao texto da Consolidação das Leis do Trabalho $(\mathrm{CLT})^{2}$.

Com efeito, a modernização das leis trabalhistas seria bem-vinda se ampliasse a proteção aos trabalhadores e garantisse condições mais saudáveis de vida para a coletividade ${ }^{3}$, até porque o texto da CLT, embora tenha sofrido atualizações ao longo do tempo, data de 1943. A própria Organização Internacional do Trabalho (OIT), segundo Beltramelli Neto, recomenda que a criação de empregos seja acompanhada da proteção dos direitos dos trabalhadores, bem como do aperfeiçoamento dos serviços sociais - a exemplo dos de saúde -, ao contrário da tendência de precarizá-los ${ }^{4}$.

Contudo, o que se vê é que a Lei n. 13.467/2017 foi elaborada para “atender aos interesses exclusivos do grande capital, em confronto com os trabalhadores e

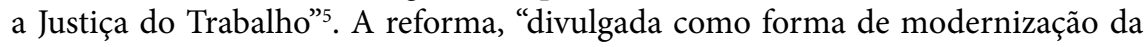
legislação trabalhista, é, em seu sentido mais profundo, antimoderna, pois tenta reverter o polo gravitacional dos direitos sociais" 6 .

Homero Batista observa que o capítulo que trata de saúde e segurança do trabalho na CLT, reformado pela última vez em 1978, foi completamente esquecido

\footnotetext{
${ }^{1}$ BRASIL. Lei n. 13.467, de 13 de julho de 2017. Altera a Consolidação das Leis do Trabalho (CLT), aprovada pelo Decreto-Lei no 5.452, de 1 o de maio de 1943, e as Leis nos 6.019, de 3 de janeiro de 1974, 8.036, de 11 de maio de 1990, e 8.212, de 24 de julho de 1991, a fim de adequar a legislação às novas relações de trabalho. Disponível em: http://www.planalto.gov.br/ccivil_03/_Ato2015-2018/2017/Lei/L13467.htm. Acesso em: 28 set. 2018.

${ }^{2}$ BRASIL. Decreto-Lei n. 5.452, de $1^{\circ}$ de Maio de 1943. Aprova a Consolidação das Leis do Trabalho. Disponível em: http://www.planalto.gov.br/ccivil_03/decreto-lei/Del5452compilado.htm. Acesso em: 28 set. 2018.

${ }^{3}$ KREIN, José Dari. O desmonte dos direitos, as novas configurações do trabalho e o esvaziamento da ação coletiva: consequências da reforma trabalhista. Tempo Social, v. 30, n. 1, p. 99, 2018. Disponível em: https://www.scielo.br/pdf/ts/v30n1/1809-4554-ts-30-01-0077.pdf. Acesso em: 25 out. 2018. https://doi. org/10.11606/0103-2070.ts.2018.138082.

${ }^{4}$ BELTRAMELLI NETO, Silvio. A reforma trabalhista e o retrocesso na proteção jurídica da saúde e segurança no trabalho: notas críticas sobre jornada e outros dispositivos alusivos ao meio ambiente laboral. Revista do Tribunal Regional do Trabalho da $15^{\text {a }}$ Região, Campinas, SP, n. 51, p. 195, jul./dez. 2017. Disponível em: https://juslaboris.tst.jus.br/bitstream/handle/20.500.12178/125458/2017_beltramelli_neto_silvio_ reforma_trabalhista.pdf?sequence=1\&isAllowed=y. Acesso em: 30 out. 2018.

5SOUTO MAIOR, Jorge Luiz. Os 201 ataques da "reforma" aos trabalhadores. Jorge Luiz Souto Maior [Blog], 08 maio 2017. Disponível em: http://www.jorgesoutomaior.com/blog/os-201-ataques-da-reforma-aostrabalhadores. Acesso em: 03 out. 2018.

${ }^{6}$ SANTOS, José Aparecido dos. Reforma trabalhista e proteção à saúde do trabalhador. Revista Eletrônica [do] Tribunal Regional do Trabalho da $9^{a}$ Região, Curitiba, v. 7, n. 64, p. 53-64, dez. 2017/jan. 2018. Disponível em: https://juslaboris.tst.jus.br/bitstream/handle/20.500.12178/124654/2017_santos_jose_reforma_ trabalhista. pdf?sequence=1\&isAllowed=y. Acesso em: 25 nov. 2018.
} 
pela Reforma Trabalhista, apesar de todos os avanços científicos e tecnológicos recentes que poderiam, por exemplo, alterar os limites de tolerância a agentes potencialmente nocivos ${ }^{7}$. Assim, o autor aduz que a omissão do legislador sobre um dos temas que mais clamavam por modernizações - o da saúde e segurança do trabalho - faz questionar se o real objetivo das alterações legislativas era mesmo melhorar as condições de trabalho ou apenas reduzir os custos operacionais8.

De fato, a reforma não respeitou os patamares mínimos previstos na Constituição Federal de 1988 (CF/88) econômico na principal relação de poder existente no âmbito da economia e da sociedade, a relação de emprego" ${ }^{\prime \prime}$.

Como bem apontado por Delgado:

$\mathrm{Na}$ verdade, os princípios constitucionais da centralidade da pessoa humana na vida real e no Direito, da dignidade da pessoa humana, da valorização do trabalho e do emprego, do bem-estar individual e social, da igualdade em sentido material e da subordinação da propriedade privada à sua função socioambiental são repetidamente negligenciados ou diretamente afrontados por diversas regras jurídicas expostas na nova $l \mathrm{i}^{11}$.

Dessa forma, constata-se que as mudanças vão de encontro aos princípios constitucionalmente assegurados relativos à proteção dos direitos e da saúde dos trabalhadores, ao permitirem um "rebaixamento das condições gerais de trabalho vetado pelo comando do caput do artigo $7^{\circ} \mathrm{da} \mathrm{CF} / 88$, do qual emana o princípio da proibição do retrocesso no âmbito das relações de trabalho"12. Nesse sentido, José Aparecido dos Santos observa que, em um país "com tantos acidentes do trabalho e doenças ocupacionais, esse novo clima jurídico deixa transparecer a trava amarga de um fracasso persistente: a marca da nossa subcidadania social"13.

Nesse contexto, a "modernização" trazida pela reforma trabalhista consiste, na realidade, no desmonte dos direitos já conquistados pelos trabalhadores, o que demonstra um verdadeiro retrocesso social. Isso porque "não há, em todo o projeto,

\footnotetext{
${ }^{7}$ SILVA, Homero Batista Mateus da. Comentários a reforma trabalhista. 1. ed. São Paulo: Editora Revista dos Tribunais, 2017. p. 8. E-book.

8/d. Ibid.

${ }^{9}$ BRASIL. Constituição da República Federativa do Brasil de 1988. Disponível em: http://www.planalto.gov. br/ccivil_03/constituicao/constituicaocompilado.htm. Acesso em: 28 set. 2018.

${ }^{10}$ DELGADO, Maurício Godinho; DELGADO, Gabriela Neves. A reforma trabalhista no Brasil: com os comentários à Lei n 13.467/2017. São Paulo: LTr, 2017, p. 41.

${ }^{11} / d$. Ibid.

${ }^{12}$ COUTINHO, Grijalbo. "Reforma" trabalhista em tempos de golpes e golpismos contra a classe trabalhadora. Jorge Luiz Souto Maior [Blog], 10 jul. 2017. Disponível em: https://www.jorgesoutomaior.com/blog/reformatrabalhista-em-tempos-de-golpes-e-golpismos-contra-a-classe-trabalhadora. Acesso em: 28 set. 2018.

${ }^{13}$ SANTOS, José Aparecido dos. op. cit., p. 53-64.
} 
nenhuma ampliação de direitos à classe trabalhadora senão o aumento exacerbado do poder da burguesia, para a definição das cláusulas dos contratos individuais ou coletivos de trabalho"14.

Importante destacar que a $\mathrm{CF} / 88$ distinguiu a saúde e o trabalho como direitos sociais. Os direitos sociais fazem parte dos "valores formadores e norteadores da identidade constitucional de uma sociedade"15. São reconhecidos como direitos garantidores da condição ou status de cidadania ${ }^{16}$. Por sua vez, Paulo Bonavides defende que a garantia dos direitos sociais deve ser interpretada como cláusula pétrea, por meio de uma interpretação extensiva dos direitos e garantias individuais elencados no artigo 60 , parágrafo $4^{\circ}$, inciso $\mathrm{IV}^{17}$.

O objetivo desse artigo é identificar e analisar as possíveis implicações da Reforma Trabalhista para a saúde do trabalhador, tendo em vista os regramentos constitucionais que garantem a saúde como direito social e que estabelecem ser dever do Estado a adoção de políticas sociais e econômicas que visem à redução dos riscos de doença e outros agravos.

Para o desenvolvimento do estudo, utilizou-se a metodologia qualitativa com adoção da técnica de análise de conteúdo de documentos. Segundo Bardin ${ }^{18}$, a análise de conteúdo pode ser conceituada como "um conjunto de técnicas de análise das comunicações que utiliza procedimentos sistemáticos e objetivos de descrição do conteúdo das mensagens”. Foram escolhidos como parâmetros para este estudo e analisados quatro tópicos alterados pela Lei n. 13.467/2017 e que precarizam as relações de trabalho, especialmente no tocante à saúde do trabalhador, quais sejam: a possibilidade de redução do intervalo intrajornada mediante negociação coletiva; a possibilidade de alterar o enquadramento do grau de insalubridade por norma coletiva; a possibilidade de trabalho em locais insalubres durante a gravidez ou fase de lactação; e a possibilidade da terceirização ampla e irrestrita.

\section{Tópicos da Reforma Trabalhista}

\section{Intervalo intrajornada}

O intervalo intrajornada, na definição de Bezerra Leite, é aquele realizado na própria jornada de trabalho, geralmente para alimentação e descanso do

\footnotetext{
${ }^{14}$ COUTINHO, Grijalbo. op. cit.

${ }^{15}$ FERNANDES, Bernardo Gonçalves. Curso de direito constitucional. 9. ed. Salvador: JusPODIVM, 2017. p. 141.

${ }^{16}$ FLEURY, Sonia; OUVERNEY, Assis Mafort. Política de saúde: uma política social. In: GIOVANELLA, Ligia et al. (Org.). Políticas e sistema de Saúde no Brasil. Rio de Janeiro: FIOCRUZ: CEBES, 2008. p. 23-64.

${ }^{17}$ BONAVIDES, Paulo. Curso de direito constitucional. 30. ed. São Paulo: Malheiros Editores, 2015. p. 676.

${ }^{18}$ BARDIN, Laurence. Análise de conteúdo. Lisboa: Edições 70, 1997. p. 42.
} 
trabalhador ${ }^{19}$. Assim, nos termos do artigo 71 da CLT, para as jornadas com duração superior a quatro horas e inferir a seis horas, o intervalo terá duração de 15 minutos. Por sua vez, aqueles que trabalham em uma jornada superior a seis horas por dia têm direito, em regra, a intervalo mínimo de uma hora e máximo de duas horas.

Tamanha sua importância, o tema sempre recebeu uma atenção especial, tanto do legislador quanto do próprio Poder Judiciário. Com efeito, o Tribunal Superior do Trabalho (TST), em sua Súmula $437^{20}$, inciso II, estabelece que o intervalo intrajornada é uma norma de ordem pública e constitui medida de saúde, segurança e higiene do trabalho, não podendo, portanto, ser reduzido ou suprimido por meio de negociação coletiva.

Já o inciso I da Súmula 437 do TST designa que, quando o empregador, de forma indevida, não concede o intervalo ou o concede com menos tempo que o mínimo, ele está obrigado a realizar, como indenização, o pagamento referente ao período total, e não apenas ao período suprimido. Além disso, o inciso III dispõe que a indenização sobre o intervalo intrajornada não concedido tem natureza salarial, $\mathrm{o}$ que implica dizer que repercute no cálculo de outras parcelas salariais.

Curiosamente, a partir da Reforma Trabalhista, o artigo 71 da CLT foi alterado, de modo a permitir tudo aquilo que era vedado pela legislação passada e pelo entendimento pacífico do TST, sedimentado na Súmula 437.

Com a nova redação do parágrafo $4^{\circ}$ do artigo 71 , a não concessão do intervalo intrajornada implica o pagamento de uma compensação de natureza indenizatória. Ou seja, o intervalo deixou de ser considerado uma parcela de natureza salarial. Ainda, o mesmo parágrafo dispõe que a indenização recairá apenas sobre o período que foi suprimido, e não sobre a totalidade do intervalo.

Já o artigo 611-A, inciso III, da CLT, inserido pela Reforma Trabalhista, passou a prever a possibilidade de redução do intervalo intrajornada mediante negociação coletiva, a despeito da expressa vedação feita pelo TST, baseada em um entendimento consolidado, elaborado "após compreendidos os problemas sociais gerados pela supressão do intervalo." ${ }^{21}$

Por sua vez, o artigo 611-B, em seu parágrafo único, também inserido pela Reforma Trabalhista, dispõe que as normas sobre duração do trabalho e intervalos não são consideradas regras de saúde, higiene e segurança, o que contraria não só os dispositivos da $\mathrm{CF} / 88$ que versam sobre a saúde do trabalhador e a dignidade da pessoa humana, mas também toda a doutrina especializada no assunto.

\footnotetext{
${ }^{19}$ LEITE, Carlos Henrique Bezerra. Curso de direito do trabalho. 8. ed. São Paulo: Saraiva, 2017. p. 510.

${ }^{20}$ TRIBUNAL SUPERIOR DO TRABALHO - TST. Súmula 437. Disponível em: https://www3.tst.jus.br/ jurisprudencia/Sumulas_com_indice/Sumulas_Ind_401_450.htmI\#SUM-437. Acesso em: 10 mar. 2021.

${ }^{21}$ SOUTO MAIOR, Jorge Luiz. op. cit.
} 
Como exemplo, Delgado, adotando a posição do Ministério Público do Trabalho (Nota Técnica 8, de 26 de junho de 2017) ${ }^{22}$, afirma que esses artigos desvinculam

a jornada de trabalho das medidas de saúde e segurança do trabalhador, como objetivo de autorizar a livre negociação de jornada e intervalo para descanso. Essas normas violam os artigos $5^{\circ}$, parágrafo $2^{\circ}$, e $7^{\circ}$, inciso XXII, da Constituição ${ }^{23}$.

Delgado defende que as normas que regem os intervalos intrajornada são, sim, regras de saúde, segurança e higiene:

De um lado, as regras legais concernentes a intervalos intrajornadas ostentam, sim, manifesta dimensão de saúde, higiene e segurança laborais da pessoa humana do trabalhador. Trata-se de constatação firme assentada pelas Ciências que se dedicam ao estudo do trabalho e do meio ambiente do trabalho e das doenças e outros malefícios (acidentes) provocados na pessoa humana envolvida na dinâmica do mundo do trabalho ${ }^{24}$.

No mesmo sentido, Henrique Correia e Elisson Miessa destacam que "as normas referentes à jornada de trabalho e aos intervalos são indispensáveis à dignidade da pessoa humana do trabalhador e devem ser tratadas como normas de indisponibilidade absoluta"25.

\section{Enquadramento do grau de insalubridade}

Algumas atividades, devido a sua natureza, expõem o trabalhador a agentes nocivos ou até mesmo colocam sua vida em risco. É o caso, respectivamente, das atividades insalubres e das atividades perigosas.

O artigo 189 da CLT considera insalubre a atividade que expõe os trabalhadores a agentes nocivos acima dos limites toleráveis; esses limites são fixados com base na natureza, na intensidade e no tempo de exposição ao agente insalubre. De acordo com o artigo 190 da CLT, a regulamentação das atividades insalubres é de competência do Ministério do Trabalho, que o faz por meio das normas regulamentadoras (NR). No caso da insalubridade, a NR 15 a enquadra em três graus: máximo, que gera direito a um adicional de $40 \%$ sobre o salário; médio, cujo adicional é de $20 \%$ sobre o salário; e mínimo, com adicional de $10 \%$ sobre o salário ${ }^{26}$.

\footnotetext{
${ }^{22}$ MINISTÉRIO PÚBLICO DO TRABALHO - MPT. Procuradoria Geral do Trabalho - PGT. Nota Técnica n. 8, de 26 de junho de 2017. Disponível em: https://mpt.mp.br/pgt/publicacoes/notas-tecnicas/nota-tecnicandeg8/@@display-file/arquivo_pdf. Acesso em: 25 out. 2018.

${ }^{23}$ DELGADO, Maurício Godinho; DELGADO, Gabriela Neves. op. cit., p. 79.

${ }^{24}$ Id. Ibid., p. 134-135.

${ }^{25}$ CORREIA, Henrique; MIESSA, Élisson. Manual da reforma trabalhista. 1. ed. Salvador: JusPODIVM, 2018. p. 223.

${ }^{26} / d$. Ibid., p. 546.
} 
O já citado artigo 611-A, inciso XII, da Reforma Trabalhista criou a possibilidade de dispor sobre o enquadramento do grau de insalubridade por meio de negociação coletiva. Assim, passou a ser possível realizar o enquadramento do grau de insalubridade de forma diversa da estabelecida nas $\mathrm{NRs}^{27}$. Dessa forma, apesar de não ser possível determinar quais atividades são insalubres ou não por meio de negociação coletiva, estas podem, agora, determinar o grau de insalubridade da atividade exercida pelo trabalhador ${ }^{28}$.

Há que se destacar, contudo, que tal possibilidade beira o absurdo. Isso porque, em primeiro lugar, o enquadramento do grau de insalubridade necessita de "avaliação técnica especializada, aferida por perícia ambiental, realizada por profissional de nível universitário, devidamente habilitado em curso de saúde e segurança do trabalho" (art. 195, CLT) ${ }^{29}$. Isto é, o nível de nocividade de um agente é uma matéria técnica, que depende de um estudo especializado. Não é, portanto, algo que possa ser livremente pactuado entre os sindicatos e o empregador, por meio de negociações coletivas ${ }^{30}$.

Ademais, as normas que dizem respeito à insalubridade são de indisponibilidade absoluta, justamente por estarem expressamente dispostas no artigo $7^{\circ}$, inciso XXII, da $\mathrm{CF} / 88^{31}$. Cabe ressaltar que, embora a Constituição, em seu artigo $7^{\circ}$, inciso XXVI, reconheça as convenções e acordos coletivos de trabalho, estas "não podem prevalecer sobre normas de ordem pública, de caráter cogente, que, portanto, versam sobre direitos indisponíveis" ${ }^{\prime 2}$, como é o caso das normas de proteção à saúde do trabalhador. Assim, o inciso do artigo 611-A da CLT, incluído pela Reforma Trabalhista e que permite o enquadramento do grau de insalubridade por meio de norma coletiva, é manifestamente ilegal ${ }^{33}$.

\section{Trabalho de grávidas e lactantes em locais insalubres}

Com o objetivo de proteger as gestantes e lactantes, os fetos e os recém-nascidos em fase de amamentação, o artigo 394-A da CLT foi alterado em 2016 para proibir, de forma definitiva, o trabalho das grávidas e lactantes em locais insalubres. Assim, caso uma mulher que exercesse suas funções em local insalubre engravidasse ou estivesse em fase de lactação, deveria ser afastada da atividade insalubre e realocada em um local salubre.

\footnotetext{
${ }^{27}$ SANTOS, José Aparecido dos. op. cit., p. 62.

${ }^{28}$ Id., loc. cit.

${ }^{29}$ DELGADO, Maurício Godinho; DELGADO, Gabriela Neves. op. cit., p. 256.

${ }^{30} / d$., loc. cit.

${ }^{31}$ Id., loc. cit.

${ }^{32}$ CORREIA, Henrique; MIESSA, Élisson. op. cit., p. 546.

${ }^{33}$ SILVA, Homero Batista Mateus da. op. cit.
} 
Com o advento da Reforma Trabalhista, este artigo do Decreto-Lei n. 5.452/1943 foi novamente alterado, passando a viger com a seguinte redação:

Art. 394-A. Sem prejuízo de sua remuneração, nesta incluído o valor do adicional de insalubridade, a empregada deverá ser afastada de: (Redação dada pela Lei n ${ }^{\circ} 13.467$, de 2017)

I - atividades consideradas insalubres em grau máximo, enquanto durar a gestação; (Incluído pela Lei no 13.467, de 2017)

II - atividades consideradas insalubres em grau médio ou mínimo, quando apresentar atestado de saúde, emitido por médico de confiança da mulher, que recomende o afastamento durante a gestação; (Incluído pela Lei no 13.467 , de 2017)

III - atividades consideradas insalubres em qualquer grau, quando apresentar atestado de saúde, emitido por médico de confiança da mulher, que recomende o afastamento durante a lactação. (Incluído pela Lei n 13.467 , de 2017).

Como se vê, de acordo com a nova legislação, uma empregada grávida será automaticamente afastada do local insalubre apenas se a atividade for considerada insalubre de grau máximo. Caso contrário, seu afastamento dependerá do fornecimento de atestado médico por parte do seu médico.

No caso das lactantes, por sua vez, não há hipótese de afastamento obrigatório, nem mesmo quando a trabalhadora está exposta ao grau máximo de insalubridade. Isso significa que as lactantes só serão afastadas de suas atividades em local insalubre caso apresentem atestado fornecido por um médico recomendando o afastamento.

A alteração desse dispositivo traz alguns problemas para a saúde da mulher. Em primeiro lugar, expor as trabalhadoras a ambientes insalubres durante a gravidez ou lactação não só pode causar prejuízos à própria mulher - o que já seria ruim o suficiente -, como também pode afetar a saúde do feto ou recém-nascido ${ }^{34}$. Como bem observa Raimundo de Melo, a restrição de trabalho em ambientes insalubres por parte das grávidas e lactantes está amparado em fundamento científico, o que foi totalmente ignorado pelo legislador da reforma ${ }^{35}$.

Além disso, cumpre ressaltar que o fornecimento de atestado médico não serve como garantia absoluta de proteção à mulher e ao feto ou recém-nascido. Isso

\footnotetext{
${ }^{34}$ MELO, Raimundo Simão de. Reforma erra ao permitir atuação de grávida e lactante em local insalubre. Conjur, 21 jul. 2017. Disponível em: https://www.conjur.com.br/2017-jul-21/reflexoes-trabalhistasreforma-erra-permitir-gravida-lactante-local-insalubre. Acesso em: 05 out. 2018.

${ }^{35}$ Id. Ibid.
} 
porque não necessariamente o médico terá conhecimento específico suficiente sobre segurança e saúde no trabalho. E mais: é muito difícil que um médico, dentro de seu consultório, consiga fazer qualquer constatação sobre a insalubridade do local de trabalho da mulher; o ideal seria que ele fizesse uma inspeção na empresa para averiguar a insalubridade in loco, o que duvidosamente ocorre na prática ${ }^{36}$.

Há um terceiro problema, que é a possibilidade de ocorrer situações discrepantes dentro de um mesmo setor da empresa. Com a nova legislação, é plenamente possível que uma empregada gestante consiga o atestado e seja afastada das atividades em área insalubre, enquanto outra, não, devendo continuar a exercer suas funções normalmente ${ }^{37}$.

Dessa forma, é evidente que "a nova disciplina denota claro retrocesso na salvaguarda jurídica da vida e da saúde da gestante e do nascituro ao inverter uma presunção absoluta de dano" ${ }^{38}$. Não à toa, a Associação Nacional dos Magistrados da Justiça do Trabalho (Anamatra), aprovou um enunciado sobre o tema durante a $2^{\mathrm{a}}$ Jornada de Direito Material e Processual do Trabalho, com a seguinte redação:

Trabalhadora gestante e lactante, artigo 394-A da CLT.

A autorização legal permitindo o trabalho da gestante e lactante em ambiente insalubre é inconstitucional e inconvencional porque violadora da dignidade humana, do direito à redução dos riscos inerentes ao trabalho, da proteção integral ao nascituro e à criança e do direito social à saúde. Ademais, o meio ambiente do trabalho saudável é direito fundamental garantido pela Constituição da República, revestido de indisponibilidade absoluta. Incidência dos arts. $1^{\circ}$, III; $6^{\circ} ; 7^{\circ}$, XXII; 196; 200; 201, II; 203, I; 225; 226 e 227 da Constituição Federal; Convenção 103 e 183 da OIT; arts. 25, I e II da DUDH ${ }^{39}$.

Portanto, fica claro que essa mudança legislativa também vai contra vários dos princípios constitucionais garantidos aos trabalhadores, como a proteção do meio ambiente do trabalho (art. 225, CF/88), o direito à redução dos riscos inerentes ao trabalho por meio de normas de saúde, higiene e segurança (art. $7^{\circ}, \mathrm{XXII}, \mathrm{CF} / 88$ ) e a proteção à saúde (arts. $6^{\circ}$ e 196, CF/88).

\footnotetext{
${ }^{36}$ MELO, Raimundo Simão de. op. cit.

${ }^{37}$ CORREIA, Henrique; MIESSA, Élisson. op. cit., p. 308.

${ }^{38}$ BELTRAMELLI NETO, Silvio. op. cit., p. 192.

${ }^{39}$ FELICIANO, Guilherme Guimarães; MIZIARA, Raphael. Enunciados da $2^{a}$ jornada de direito material e processual do trabalho organizados por assunto. Disponível em: https://drive.google.com/file/d/1oZL9_ JohYjNInVvehEzYDp-bIOfcF6i6/view. Acesso em: 05 out. 2018.
} 


\section{Terceirização ampla e irrestrita}

A terceirização, como o próprio nome indica, é o fenômeno que consiste em uma empresa contratar um terceiro - no caso, outra empresa com pessoal próprio - para prestar serviços que normalmente seriam realizados por seus empregados ${ }^{40}$.

Delgado explica:

A terceirização provoca uma relação trilateral em face da contratação de força de trabalho no mercado capitalista: o obreiro, prestador de serviços, que realiza suas atividades materiais e intelectuais junto à empresa tomadora de serviços; a empresa terceirizante, que contrata este obreiro, firmando com ele os vínculos jurídicos trabalhistas pertinentes; a empresa tomadora de serviços, que recebe a prestação de labor, mas não assume a posição clássica de empregadora desse trabalhador envolvido ${ }^{41}$.

Assim, diferentemente de uma relação normal de emprego, entre empregado e empregador, a terceirização implica uma relação entre três personagens: o empregado, a empresa prestadora de mão de obra e a empresa tomadora de serviços. Entre duas empresas (prestadora e tomadora de serviços), existe um contrato de prestação de serviços, regido pelo Código Civil. Por outro lado, entre o trabalhador e a empresa prestadora de serviços, há um contrato de direito do trabalho. Cabe ressaltar que os trabalhadores subordinam-se apenas à empresa prestadora de serviços, e não à empresa tomadora de seus serviços ${ }^{42}$.

Nos últimos anos, a terceirização tem sido cada vez mais utilizada, por ser uma forma de "diminuir os custos e melhorar a qualidade do produto ou serviço" Apesar disso, existem inúmeras críticas a sua utilização, por ser considerada uma forma de precarização dos direitos do trabalhador por não haver obrigatoriedade de os terceirizados terem salários equiparados aos de empregados diretos que exerçam as mesmas funções.

A despeito da utilização em massa da terceirização, a matéria só passou a ser regulamentada em 2011, quando o TST editou a Súmula 331. Resumidamente, essa Súmula considerava lícita a terceirização desde que não fosse para as atividades-fim da empresa. Ou seja, só era possível terceirizar atividades que não fossem atividades consideradas principais. ${ }^{44}$

\footnotetext{
${ }^{40}$ LEITE, Carlos Henrique Bezerra. op. cit., p. 338.

${ }^{41}$ DELGADO, Maurício Godinho. Curso de direito do trabalho. 16. ed. São Paulo: LTr, 2017. p. 502.

${ }^{42}$ JORGE NETO, Francisco Ferreira; CAVALCANTE, Jouberto de Quadros Pessoa. A terceirização, o Direito do Trabalho e a Lei 13.429/17. GenJurídico, 08 maio 2017. Disponível em: http://genjuridico.com. br/2017/05/08/terceirizacao-o-direito-trabalho-e-lei-13-429171/. Acesso em: 25 out. 2018.

${ }^{43}$ BARROS, Alice Monteiro de. Curso de direito do trabalho. 10. ed. São Paulo: LTr, 2016. p. 300.

${ }^{44}$ CORREIA, Henrique; MIESSA, Élisson. op. cit., p. 1112.
} 
Contudo, a Lei n. $13.429 / 2017^{45}$ passou a regular o trabalho temporário e a terceirização a partir de março de 2017. Alguns meses depois, em novembro do mesmo ano, foi promulgada a Reforma Trabalhista, que alterou alguns dispositivos dessa lei com o objetivo de prever, de maneira clara, a licitude da terceirização de atividades-fim, passando a permitir a terceirização ampla e irrestrita ${ }^{46}$.

Assim, no atual ordenamento jurídico brasileiro, a terceirização é lícita independentemente de seu objeto, desde que não haja subordinação direta entre a empresa tomadora e o trabalhador. Essa alteração tem gerado enormes críticas. Em primeiro lugar, com a licitude da terceirização ampla e irrestrita, é possível que o mercado de trabalho passe a ser "desastroso e difícil para o trabalhador, já que é previsível que haja uma migração do trabalho realizado por um empregado direto da empresa tomadora de serviços para a mão de obra terceirizada" ${ }^{47}$.

Importante destacar que dados apontam que a maior parte dos acidentes de trabalho acontece com trabalhadores terceirizados. Ao terceirizar, as tomadoras transferem para as prestadoras de serviço a responsabilidade pelos riscos do trabalho, "isto é, terceirizam-se ou mesmo quarterizam-se os riscos impostos por sua atividade de trabalho para empresas, que nem sempre têm condições tecnológicas e econômicas para gerenciá-los" ${ }^{48}$. Nesse sentido, Wilson Fernandes afirma que cerca de $70 \%$ a $80 \%$ dos acidentes de trabalho no país envolvem trabalhadores terceirizados ${ }^{49}$.

Outro ponto que merece destaque e que tem consequências para a saúde dos trabalhadores é o fato de, na prática, existir tratamento diferenciado entre os empregados da empresa e os terceirizados, que não são reconhecidos como pertencentes à empresa para a qual prestam serviço. Assim, o dia a dia dos terceirizados é marcado por "condições de trabalho degradantes, falta de equipamento adequado, refeitórios diferenciados, portarias, vestiários, banheiros, uniformes e outras marcas

\footnotetext{
${ }^{45}$ BRASIL. Lei n. 13.429, de 31 de março de 2017. Altera dispositivos da Lei $n^{\circ} 6.019$, de 3 de janeiro de 1974, que dispõe sobre o trabalho temporário nas empresas urbanas e dá outras providências; e dispõe sobre as relações de trabalho na empresa de prestação de serviços a terceiros .Disponível em: http://www. planalto.gov.br/ccivil_03/_Ato2015-2018/2017/Lei/L13429.htm. Acesso em: 28 set. 2018.

${ }^{46}$ CORREIA, Henrique; MIESSA, Élisson. op. cit., p. 1112.

${ }^{47} \mathrm{RE} G O$, Évellyn Barbosa. A terceirização e a reforma trabalhista no Brasil: uma análise crítica da possibilidade de terceirização das atividades-fim. Revista Jus Navigandi, Teresina, ano 23, n. 5521, 13 ago. 2018. Disponivel em: https://jus.com.br/artigos/66910. Acesso em: 25 out. 2018.

${ }^{48}$ TERCEIRIZAÇÃO e desenvolvimento: uma conta que não fecha: dossiê acerca do impacto da terceirização sobre os trabalhadores e propostas para garantir a igualdade de direitos. Secretaria Nacional de Relações de Trabalho e Departamento Intersindical de Estatística e Estudos Socioeconômicos. São Paulo: Central Única dos Trabalhadores, 2014. p. 25. Disponível em: https://www.cut.org.br/system/uploads/ck/files/ Dossie-Terceirizacao-e-Desenvolvimento.pdf.

${ }^{49}$ BOEHM, Camila. Lei da terceirização vai precarizar trabalho, diz presidente do TRT-2. Agência Brasil, São Paulo, 23 mar. 2017. Disponível em: http://agenciabrasil.ebc.com.br/politica/noticia/2017-03/lei-daterceirizacao-vai-precarizar-trabalho-diz-presidente-do-trt-2. Acesso em: 20 out. 2018.
} 
de diferenciação" ${ }^{50}$. Em decorrência disso, esses trabalhadores estão mais suscetíveis a sofrer de estresse, doenças relacionadas ao trabalho e risco ocupacional, sofrimento psíquico e falta de suporte à saúde e à segurança ${ }^{51}$.

Destarte, ao permitir a terceirização geral, inclusive sobre as atividades-fim de uma empresa, o legislador abre espaço para um aumento no índice de acidentes de trabalho, doenças ocupacionais e outros riscos relacionados à segurança e saúde do trabalhador, violando vários princípios constitucionais que garantem a proteção desses direitos.

\section{Implicações à saúde do trabalhador}

O Brasil ratificou a Convenção 155 da OIT, promulgada por meio do Decreto n. $1.254 / 1994^{52}$, que estabelece normas e princípios acerca da saúde e segurança do trabalhador:

Outros dispositivos desta convenção estabelecem a obrigatoriedade de adoção de uma política nacional em matéria de segurança e saúde dos trabalhadores e do meio ambiente de trabalho, com o objetivo de prevenir os acidentes e os danos à saúde decorrentes do exercício do trabalho, reduzindo ao mínimo possível as causas dos riscos inerentes ao meio ambiente de trabalho $^{53}$. (Grifo nosso)

Dessa forma, as normas referentes à saúde são consideradas normas de ordem pública, não podendo ser afastadas ou derrogadas pela vontade das partes. Com isso, a CLT, bem como todas as demais normas que versam sobre a saúde, ainda que oriundas de tratados ou convenções internacionais, devem se compatibilizar com os dispositivos da $\mathrm{CF} / 88^{54}$.

\footnotetext{
${ }^{50}$ LIMA, J. A terceirização e os trabalhadores: revisitando algumas questões. Cadernos de Psicologia Social do Trabalho, v. 13, n. 1, p. 23, 1 jan. 2010. Disponível em: https://www.revistas.usp.br/cpst/article/ view/25735/27468. Acesso em: 30 out. 2018. https://doi.org/10.11606/issn.1981-0490.v13i1p17-26.

${ }^{51}$ MANDARINI, Marina Bernardo; ALVES, Amanda Martins; STICCA, Marina Greghi. Terceirização e impactos para a saúde e trabalho: uma revisão sistemática da literatura. Rev. Psicol., Organ. Trab., Brasília-DF, v. 16, n. 2, p. 143-152, jun. 2016. Disponível em: http://pepsic.bvsalud.org/scielo.php?script=sci_ar ttext\&pid=S1984-66572016000200004. Acesso em: 25 out. 2018. http://dx.doi.org/ 10.17652/ rpot/2016.2.661.

${ }^{52}$ BRASIL. Decreto n. 1.254, de 29 de setembro de 1994. Promulga a Convenção número 155, da Organização Internacional do Trabalho, sobre Segurança e Saúde dos Trabalhadores e o Meio Ambiente de Trabalho, concluída em Genebra, em 22 de junho de 1981. Disponível em: http://www.planalto.gov.br/ccivil_03/ decreto/1990-1994/D1254.htm>. Acesso em: 25 out. 2018.

${ }^{53}$ TEIXEIRA, João Carlos. A legislação de saúde do trabalhador aplicável e vigente no Brasil. Revista do Ministério Público do Trabalho, ano XI, n. 21, mar. 2021. Disponível em: http://www.anpt.org.br/ attachments/article/2732/Revista\%20MPT\%20-\%20Edi\%C3\%A7\%C3\%A3o\%2021.pdf. Acesso em: 02 out. 2018.

${ }^{54}$ CASSAR, Vólia Bomfim. Direito do trabalho. 14. ed. Rio de Janeiro: Forense, 2017.
} 
Infelizmente, como visto, as alterações promovidas pela Reforma Trabalhista não respeitaram as normas relativas à saúde, higiene e segurança existentes no ordenamento jurídico brasileiro e internacional. As consequências, por sua vez, deverão ser suportadas pelos trabalhadores, que, após anos de lutas para conquistar seus direitos, os têm novamente ameaçados pela edição de leis que não seguem os patamares mínimos de proteção assegurados pela $\mathrm{CF} / 88$.

Sandro Carvalho aponta ser difícil antever os impactos de mudanças tão radicais como as que foram feitas por meio da Lei n. 13.467/2017, já que, "muitas vezes, diferentes dispositivos podem atuar em direções opostas, impedindo que se preveja o resultado final do conjunto" ${ }^{\prime 5}$. Desta forma, embora não seja possível prever com total certeza os possíveis impactos que a reforma causará no longo prazo, é possível fazer alguns apontamentos, baseados em diversos estudos sobre a saúde do trabalhador.

Em primeiro lugar, a possibilidade de reduzir o intervalo intrajornada mediante negociação coletiva afeta diretamente a saúde física e mental do trabalhador. Isso porque o objetivo desse intervalo é justamente possibilitar sua alimentação e seu descanso, visando a "proteger a integridade física e psíquica do trabalhador (ordem biológica), evitando-lhe a fadiga e possíveis problemas de saúde decorrentes do intenso esforço físico e/ou mental que o labor diário e o estresse possam originar" ${ }^{36}$.

Assim, ao possibilitar a redução do intervalo intrajornada, torna-se mais provável o surgimento de problemas de saúde, bem como aumenta a probabilidade de acidentes em razão da desatenção e do cansaço ${ }^{57}$. Costa, Costa e Cintra observam que, no caso de redução do intervalo intrajornada para o mínimo de 30 minutos, o trabalhador seria obrigado a se alimentar de maneira rápida, o que refletiria em má digestão e má escolha de alimentos, estresse, pressa e outros fatores que interferem na qualidade de vida ${ }^{58}$.

Lado outro, permitir o trabalho de grávidas e lactantes em locais insalubres coloca não só a trabalhadora em risco, como também o feto ou o recém-nascido. Viola, dessa forma, o próprio princípio da dignidade humana ao apresentar um risco tanto à mulher quanto às futuras gerações.

\footnotetext{
${ }^{55}$ CARVALHO, Sandro Sacchet de. Uma visão geral sobre a reforma trabalhista. Boletim Mercado de Trabalho Conjuntura e Análise, Brasília-DF, n. 63, p. 81, 2017. Disponível em: http://www.ipea.gov.br/portal/images/ stories/PDFs/mercadodetrabalho/171024_bmt_63_07_politica_em_foco_visao_geral.pdf. Acesso em: 26 out. 2018.

${ }^{56}$ LEITE, Carlos Henrique Bezerra. op. cit., p. 495.

${ }^{57}$ COSTA, Beliza Souza; COSTA, Sueli de Souza; CINTRA, Cynthia Leonis Dias. Os possíveis impactos da reforma da legislação trabalhista na saúde do trabalhador. Rev Bras Med Trab., v. 16, n. 1, p. 109-117, 2018. Disponível em: https://cdn.publisher.gn1.link/rbmt.org.br/pdf/v16n1a16.pdf. Acesso em: 25 out. 2018. http://dx.doi.org/: 10.5327/Z1679443520180097. p. 115.

${ }^{58}$ Id., loc. cit.
} 
Como exemplo, o trabalho em ambiente muito barulhento, onde a exposição a ruídos seja acima do tolerável, é considerado insalubre de acordo com a NR15, expedida pelo Ministério do Trabalho e que trata da saúde no ambiente de trabalho. Segundo a Sociedad Española de Ginecología y Obstetricia (SEGO), expor a trabalhadora com mais de 20 semanas de gravidez a ruídos acima de 80 decibéis pode causar danos ao sistema auditivo do bebê. Ademais, a exposição a barulhos muito altos "leva o organismo da mãe a produzir hormônios ligados ao estresse, fazendo o coração acelerar, o que pode causar mal ao bebê" ${ }^{\prime \prime}$.

Quanto à possibilidade de alterar o enquadramento da insalubridade por meio de negociação coletiva, cabe ressaltar que a própria CLT estabelece que a caracterização e a classificação da insalubridade devem ser feitas por um médico ou engenheiro do trabalho, ou seja, profissionais que possuem os conhecimentos técnicos necessários para delimitar as atividades insalubres e os níveis máximos de tolerância. Permitir que o grau de insalubridade seja acordado mediante negociação coletiva, entre pessoas que, em sua maioria, não detêm o conhecimento técnico e científico necessário para tal, abre portas para o acometimento de doenças e acidentes do trabalho. Há que se levar em consideração que a proteção da saúde não se resume ao combate de doenças, mas inclui também a eliminação de exposição ao risco ${ }^{60}$. Nesse ponto, a Reforma Trabalhista é uma verdadeira ameaça à saúde do trabalhador.

Por fim, quanto à terceirização ampla e irrestrita, já é sabido que a terceirização expõe $\mathrm{o} / \mathrm{a}(\mathrm{s})$ trabalhador/a(s) a maior rotatividade, a salários mais baixos e de curta duração e a piores condições de trabalho, o que resulta em maiores índices de acidentes de trabalho, inclusive fatais ${ }^{61}$.

A diferenciação no tratamento entre trabalhadores diretos e terceirizados os coloca em posição de desigualdade, que, de maneira geral, resulta para os terceirizados: insuficiência de qualificação e capacitação, falta de treinamento e não fornecimento de equipamentos para proteção individual (EPI), dentre outros fatores que contribuem para o aumento de doenças e acidentes de trabalho ${ }^{62}$.

\footnotetext{
${ }^{59}$ CABRAL-DONEDA, Luciana. Gravidez de muitos riscos: insalubridade no emprego aprovada por lei. Colabora, 15 ago. 2017. Disponivel em: https://projetocolabora.com.br/ods3/gravidez-de-muitos-riscos/. Acesso em: 26 out. 2018.

${ }^{60}$ BELTRAMELLI NETO, Silvio. op. cit., p. 197.

${ }^{61} \mathrm{HECK}$, Fernando Mendonça. Entrevista - reforma trabalhista e os seus impactos para a saúde do $\backslash a(\mathrm{~s})$ trabalhador $\backslash a(s)$, com Edvânia Ângela de Souza Lourenço. Pegada, a revista da geografia do trabalho, v. 19, n. 1, p. 267, jan./abr. 2018. Disponível em: https://revista.fct.unesp.br/index.php/pegada/article/ download/5821/4448. Acesso em: 25 nov. 2018. https://doi.org/10.33026/peg.v19i1.5821.

${ }^{62}$ DRUCK, Graça. A terceirização sem limites: mais precarização e riscos de morte aos trabalhadores. In: FILGUEIRAS, Vitor Araújo (Org.). Saúde e segurança do trabalho no Brasil. Brasília-DF: Gráfica Movimento, 2017. p. 199.
} 
Além disso, a precarização do trabalho como consequência da terceirização coloca o trabalhador em uma posição de maior suscetibilidade a depressão, estresse, transtornos psicossomáticos e doenças relacionadas a esforços repetitivos em decorrência do trabalho, como a lesão por esforço repetitivo (LER) ${ }^{63}$.

Frente ao exposto, fica claro que a Reforma Trabalhista, defendida pelo governo como uma forma de "modernizar" as relações trabalhistas, não passa de uma forma de "aprofundar os níveis de exploração e subserviência do/a trabalhador/a ao capital, sem a necessidade de respeitar parâmetros sociais e de saúde"64.

Ao permitir essas alterações na lei, o governo está legitimando o desrespeito às normas de segurança e saúde dos trabalhadores, contribuindo para a precarização do trabalho e para o adoecimento da massa trabalhadora, o que passa a ser um problema de saúde pública.

\section{Conclusão}

A Reforma Trabalhista alterou diversos artigos da CLT, estabelecendo novas regras que, em grande parte, são contrárias ao que era adotado anteriormente e representando uma mudança de posicionamento extrema. Além disso, nas quatro alterações analisadas por este estudo, o legislador pouco se importou em respeitar as disposições constitucionais que asseguram um patamar mínimo de proteção aos direitos dos trabalhadores, especificamente no tocante à saúde.

Ora, a saúde é um direito social (art. $6^{\circ}, \mathrm{CF} / 88$ ), direito de todos e dever do Estado, devendo ser garantido por meio de políticas econômicas e sociais que pretendam reduzir o risco de doenças (art. 196, CF/88). E, ainda, é direito dos trabalhadores a redução de riscos inerentes ao trabalho, mediante normas de saúde, higiene e segurança (art. $7^{\circ}, \mathrm{XXII}, \mathrm{CF} / 88$ ).

Todavia, o que se constata é que, ao permitir a redução do intervalo intrajornada por meio de negociação coletiva; o trabalho de gestantes/lactantes em locais insalubres; o enquadramento do grau de insalubridade mediante negociação coletiva; e a terceirização ampla e irrestrita, a Reforma Trabalhista criou regras que não se preocupam em preservar a saúde, a segurança e a qualidade de vida dos trabalhadores.

Ao contrário, verifica-se que o objetivo da nova lei é desconstruir a estrutura constitucional e infraconstitucional de proteção à saúde do trabalhador, "por meio

\footnotetext{
${ }^{63}$ AQUINO, Cassio Adriano Braz et al. Terceirização e saúde do trabalhador: uma revisão da literatura nacional. Rev. Psicol., Organ. Trab., Brasília, v. 16, n. 2, p. 133, jun. 2016. Disponível em: http://pepsic.bvsalud.org/ pdf/rpot/v16n2/v16n2a03.pdf. Acesso em: 25 out. 2018. http://dx.doi.org/10.17652/rpot/2016.2.660.

${ }^{64}$ HECK, Fernando Mendonça. op. cit., p. 261.
} 
de regras explícitas nessa direção, que diminuem a incidência das normas redutoras dos riscos inerentes à saúde e segurança no trabalho" ${ }^{65}$.

Nesse contexto, verifica-se também a prevalência dos interesses do capital frente às normas relativas à saúde, higiene e segurança do trabalho, revelando o verdadeiro objetivo por trás da "modernização" das leis trabalhistas. Se, por um lado, o crescimento econômico de um país é fundamental para seu desenvolvimento e, portanto, deve ser estimulado, por outro, esse crescimento não pode se basear no desrespeito às normas constitucionais, sobretudo nas que dizem respeito à saúde $\mathrm{e}$ à dignidade da pessoa humana.

\section{Referências}

AQUINO, Cassio Adriano Braz et al. Terceirização e saúde do trabalhador: uma revisão da literatura nacional. Rev. Psicol., Organ. Trab., Brasília, v. 16, n. 2, p. 133, jun. 2016. Disponível em: http://pepsic.bvsalud.org/pdf/rpot/v16n2/v16n2a03.pdf. Acesso em: 25 out. 2018. http://dx.doi.org/10.17652/rpot/2016.2.660.

BARDIN, Laurence. Análise de conteúdo. Lisboa: Edições 70, 1997.

BARROS, Alice Monteiro de. Curso de direito do trabalho. 10. ed. São Paulo: LTr, 2016.

BELTRAMELLI NETO, Silvio. A reforma trabalhista e o retrocesso na proteção jurídica da saúde e segurança no trabalho: notas críticas sobre jornada e outros dispositivos alusivos ao meio ambiente laboral. Revista do Tribunal Regional do Trabalho da 15a Região, Campinas, SP, n. 51, p. 183-202, jul./dez. 2017. Disponível em: https://juslaboris.tst.jus.br/ bitstream/handle/20.500.12178/125458/2017_beltramelli_neto_silvio_reforma_trabalhista. pdf? sequence $=1$ \&isAllowed $=$ y. Acesso em: 30 out. 2018.

BOEHM, Camila. Lei da terceirização vai precarizar trabalho, diz presidente do TRT-2. Agência Brasil, São Paulo, 23 mar. 2017. Disponível em: http://agenciabrasil.ebc.com.br/ politica/noticia/2017-03/lei-da-terceirizacao-vai-precarizar-trabalho-diz-presidente-do-trt-2. Acesso em: 20 out. 2018.

BONAVIDES, Paulo. Curso de direito constitucional. 30. ed. São Paulo: Malheiros Editores, 2015.

CABRAL-DONEDA, Luciana. Gravidez de muitos riscos: insalubridade no emprego aprovada por lei. Colabora, 15 ago. 2017. Disponível em: https://projetocolabora.com.br/ods3/gravidezde-muitos-riscos/. Acesso em: 26 out. 2018.

CARVALHO, Sandro Sacchet de. Uma visão geral sobre a reforma trabalhista. Boletim Mercado de Trabalho - Conjuntura e Análise, Brasília-DF, n. 63, p. 81-92, 2017. Disponível em: http://www.ipea.gov.br/portal/images/stories/PDFs/mercadodetrabalho/171024_bmt_63_07_ politica_em_foco_visao_geral.pdf. Acesso em: 26 out. 2018.

\footnotetext{
${ }^{65}$ DELGADO, Maurício Godinho; DELGADO, Gabriela Neves. op. cit., p. 42.
} 
CASSAR, Vólia Bomfim. Direito do trabalho. 14. ed. Rio de Janeiro: Forense, 2017.

CORREIA, Henrique; MIESSA, Élisson. Manual da reforma trabalhista. 1. ed. Salvador: JusPODIVM, 2018.

COSTA, Beliza Souza; COSTA, Sueli de Souza; CINTRA, Cynthia Leonis Dias. Os possíveis impactos da reforma da legislação trabalhista na saúde do trabalhador. Rev Bras Med Trab., v. 16, n. 1, p. 109-117, 2018. Disponível em: https://cdn.publisher.gn1. link/rbmt.org.br/pdf/v16n1a16.pdf. Acesso em: 25 out. 2018. http://dx.doi.org/: 10.5327/ Z1679443520180097.

COUTINHO, Grijalbo. "Reforma” trabalhista em tempos de golpes e golpismos contra a classe trabalhadora. Jorge Luiz Souto Maior [Blog], 10 jul. 2017. Disponível em: https://www.jorgesoutomaior.com/blog/reforma-trabalhista-em-tempos-de-golpes-egolpismos-contra-a-classe-trabalhadora. Acesso em: 28 set. 2018.

DELGADO, Maurício Godinho. Curso de direito do trabalho. 16. ed. São Paulo: LTr, 2017.

DELGADO, Maurício Godinho; DELGADO, Gabriela Neves. A reforma trabalhista no Brasil: com os comentários à Lei no 13.467/2017. São Paulo: LTr, 2017.

DRUCK, Graça. A terceirização sem limites: mais precarização e riscos de morte aos trabalhadores. In: FILGUEIRAS, Vitor Araújo (Org.). Saúde e segurança do trabalho no Brasil. Brasília-DF: Gráfica Movimento, 2017. p. 183-204.

FELICIANO, Guilherme Guimarães; MIZIARA, Raphael. Enunciados da $2^{a}$ jornada de direito material e processual do trabalho organizados por assunto. Disponível em: https://drive.google.com/file/d/1oZL9_JohYjNInVvehEzYDp-bl0fcF6i6/view. Acesso em: 05 out. 2018.

FERNANDES, Bernardo Gonçalves. Curso de direito constitucional. 9. ed. Salvador: JusPODIVM, 2017.

FLEURY, Sonia; OUVERNEY, Assis Mafort. Política de saúde: uma política social. In: GIOVANELLA, Ligia et al. (Org.). Políticas e sistema de Saúde no Brasil. Rio de Janeiro: FIOCRUZ: CEBES, 2008. p. 23-64.

HECK, Fernando Mendonça. Entrevista - reforma trabalhista e os seus impactos para a saúde dola(s) trabalhador $\backslash a(s)$, com Edvânia Ângela de Souza Lourenço. Pegada, a revista da geografia do trabalho, v. 19, n. 1, p. 258-273, jan./abr. 2018. Disponível em: https://revista.fct.unesp.br/index.php/pegada/article/download/5821/4448. Acesso em: 25 nov. 2018. https://doi.org/10.33026/peg.v19i1.5821.

JORGE NETO, Francisco Ferreira; CAVALCANTE, Jouberto de Quadros Pessoa. A terceirização, o Direito do Trabalho e a Lei 13.429/17. GenJurídico, 08 maio 2017. Disponível em: http://genjuridico.com.br/2017/05/08/terceirizacao-o-direito-trabalho-e-lei-13-429171/. Acesso em: 25 out. 2018. 
KREIN, José Dari. O desmonte dos direitos, as novas configurações do trabalho e o esvaziamento da ação coletiva: consequências da reforma trabalhista. Tempo Social, v. 30, n. 1, p. 77-104, 2018. Disponível em: https://www.scielo.br/pdf/ts/v30n1/18094554-ts-30-01-0077.pdf. Acesso em: 25 out. 2018. https://doi.org/10.11606/0103-2070. ts.2018.138082.

LEITE, Carlos Henrique Bezerra. Curso de direito do trabalho. 8. ed. São Paulo: Saraiva, 2017.

LIMA, J. A terceirização e os trabalhadores: revisitando algumas questões. Cadernos de Psicologia Social do Trabalho, v. 13, n. 1, p. 17-26, 1 jan. 2010. Disponível em: https://www.revistas.usp.br/cpst/article/view/25735/27468. Acesso em: 30 out. 2018. https://doi.org/10.11606/issn.1981-0490.v13i1p17-26.

LOURENÇO, Edvânia Ângela de Souza. Terceirização: a derruição de direitos e a destruição da saúde dos trabalhadores. Serv. Soc. Soc., São Paulo, n. 123, p. 447-475, set. 2015. Disponível em: http://www.scielo.br/pdf/sssoc/n123/0101-6628-sssoc-123-0447.pdf. Acesso em: 29 out. 2018. http://dx.doi.org/10.1590/0101-6628.032.

MANDARINI, Marina Bernardo; ALVES, Amanda Martins; STICCA, Marina Greghi. Terceirização e impactos para a saúde e trabalho: uma revisão sistemática da literatura. Rev. Psicol., Organ. Trab., Brasília-DF, v. 16, n. 2, p. 143-152, jun. 2016. Disponível em: http://pepsic.bvsalud.org/scielo.php?script=sci_arttext\&pid=S1984-66572016000200004. Acesso em: 25 out. 2018. http://dx.doi.org/ 10.17652/rpot/2016.2.661.

MELO, Raimundo Simão de. Reforma erra ao permitir atuação de grávida e lactante em local insalubre. Conjur, 21 jul. 2017. Disponível em: https://www.conjur.com.br/2017-jul-21/ reflexoes-trabalhistas-reforma-erra-permitir-gravida-lactante-local-insalubre. Acesso em: 05 out. 2018.

RÊGO, Évellyn Barbosa. A terceirização e a reforma trabalhista no Brasil: uma análise crítica da possibilidade de terceirização das atividades-fim. Revista Jus Navigandi, Teresina, ano 23, n. 5521, 13 ago. 2018. Disponível em: https://jus.com.br/artigos/66910. Acesso em: 25 out. 2018.

SANTOS, José Aparecido dos. Reforma trabalhista e proteção à saúde do trabalhador. Revista Eletrônica [do] Tribunal Regional do Trabalho da $9^{a}$ Região, Curitiba, v. 7, n. 64, p. 53-64, dez. 2017/jan. 2018. Disponível em: https://juslaboris.tst.jus.br/bitstream/ handle/20.500.12178/124654/2017_santos_jose_reforma_trabalhista.pdf?sequence $=1$ \&isAllowed $=\mathrm{y}$. Acesso em: 25 nov. 2018.

SILVA, Homero Batista Mateus da. Comentários a reforma trabalhista. 1. ed. São Paulo: Editora Revista dos Tribunais, 2017. E-book.

SOUTO MAIOR, Jorge Luiz. Os 201 ataques da "reforma" aos trabalhadores. Jorge Luiz Souto Maior [Blog], 08 maio 2017. Disponível em: http://www.jorgesoutomaior.com/blog/os-201ataques-da-reforma-aos-trabalhadores. Acesso em: 03 out. 2018. 
TEIXEIRA, João Carlos. A legislação de saúde do trabalhador aplicável e vigente no Brasil. Revista do Ministério Público do Trabalho, ano XI, n. 21, mar. 2001. Disponivel em: http://www.anpt.org.br/attachments/article/2732/Revista\%20MPT\%20-\%20Edi\%C3\% A7\%C3\%A3o\%2021.pdf. . Acesso em: 02 out. 2018.

TERCEIRIZAÇÃO e desenvolvimento: uma conta que não fecha: dossiê acerca do impacto da terceirização sobre os trabalhadores e propostas para garantir a igualdade de direitos. Secretaria Nacional de Relações de Trabalho e Departamento Intersindical de Estatística e Estudos Socioeconômicos. São Paulo: Central Única dos Trabalhadores, 2014. Disponível em: https://www.cut.org.br/system/uploads/ck/files/Dossie-Terceirizacao-eDesenvolvimento.pdf.

Julia Oliveira Damasceno - Especialização em Direito Público pela Faculdade Arnaldo; graduação em Direito pela Universidade Federal de Minas Gerais (UFMG). Belo Horizonte/ MG, Brasil.E-mail: juliadamasceno@hotmail.com

Carolina Pinheiro Batista - Mestrado em Administração pela Universidade FUMEC; graduação em Direito pela Universidade FUMEC. Professora de metodologia e orientadora dos cursos de pós-graduação do Supremo. Belo Horizonte/ MG, Brasil. E-mail: carolcpb@gmail.com

Ana Maria Caldeira Oliveira - Doutorado e mestrado em Saúde Pública pela Faculdade de Saúde Pública da Universidade de São Paulo (FSP-USP). Belo Horizonte/MG, Brasil. E-mail: anamariacaldeira@pbh.gov.br 